\title{
The postshock activity burst
}

\author{
MICHAEL S. FANSELOW \\ Dartmouth College, Hanover, New Hampshire
}

\begin{abstract}
When a rat receives an electric shock delivered to the floor of an enclosure, it reacts with frenzied activity. On shock termination, the activity persists for a brief period of time and then gradually gives way to a period of freezing. Subsequent grid shocks temporarily disrupt freezing, with the length of disruption determined by shock intensity (Experiment 1). The duration of this activity burst depends predominantly on the test shock intensity but not on the training shock intensity. The reverse is true for the probability of freezing, which is positively related to training shock intensity (Experiment 2). Based on this finding, it is argued that the activity burst is a UR, while freezing is a CR. Further support that freezing is a CR is provided by Experiment 3, which demonstrates that a delay, during which the rat is out of the shock-associated context, between the training and testing periods does not disrupt freezing. A topographical analysis of the behaviors making up the activity burst is provided by Experiment 4. The postshock activity burst was composed predominantly of head movement, turning, and rearing.
\end{abstract}

When a rat receives an aversive electric shock through the grid floor of an enclosure, it reacts with vigorous activity. Following the shock, this activity persists for a brief period of time and then gradually gives way to a period of inactivity that is referred to as freezing (Myer, 1971). This pattern is particularly apparent in a rat that is already freezing because of past experience with shock in the test chamber. The shock disrupts freezing, and freezing does not resume for several seconds following shock offset (Bolles, 1975, pp. 362-363; Bolles \& Riley, 1973).

The freezing component of this postshock reaction has received considerable experimental attention (e.g., Blanchard \& Blanchard, 1969; Blanchard, Dielman, \& Blanchard, 1968; Bolles \& Collier, 1976; Fanselow \& Bolles, 1979a). Of particular interest is that this freezing behavior appears to be a conditioned response (CR) to situational cues paired with shock and is not elicited by the shock itself (Fanselow, 1980). The activity component of this reaction, and its ability to disrupt freezing temporarily, have not received the same degree of experimental investigation. This paper reports a series of experiments that constitute a preliminary investigation of the activity component of the postshock reaction.

\section{EXPERIMENT 1}

Anisman and Waller (1973), using an activity rating scale, found rats to be more active $5 \mathrm{sec}$ after a strong shock $(1.0 \mathrm{~mA})$ than after a mild shock $(.3$ or

Address reprint requests to M. S. Fanselow, Department of Psychology, Dartmouth College, Hanover, New Hampshire 03755. I thank R. A. Sigmundi and R. C. Bolles for their comments on an earlier draft of this paper.
$.5 \mathrm{~mA})$. However, $30 \mathrm{sec}$ after shock, the rats that received strong shock were less active than the others. The results at $30 \mathrm{sec}$ were probably due to the fact that freezing increases with shock intensity (e.g., Fanselow \& Bolles, 1979a). Anisman and Waller's results at 5 sec suggest that the more intense shock may also produce a greater activity component of the postshock reaction and therefore may be more successful than milder shocks at disrupting freezing. Rather than looking at the level of activity during the activity burst, as Anisman and Waller did, the present studies examined the duration of the activity burst.

The first experiment was designed to determine if the ability of shock to disrupt freezing is a function of shock intensity. One day before the test day, all the rats were exposed to the same shock in a novel test chamber. This training was done to generate a base rate of freezing for the test session. During the test, the rats received a single shock, with different groups receiving different intensities. Latency to freeze following the test shock was taken as a measure of the ability of shock to disrupt freezing.

\section{Method}

Subjects. Twenty-four naive female rats of Long-Evans descent (Blue Spruce Farms, Altamont, New York) were divided into three groups of equal size. The rats were between 90 and 110 days old at the start of the experiment and were individually housed with ad-lib access to laboratory chow and water. All the experiments reported here were conducted during the lights-on portion of a 14-h-on/10-h-off light/dark cycle.

Apparatus. The test chamber was a $23.5-\mathrm{cm}$-long, 29-cm-wide, and 19.5-cm-high operant chamber. The front and back walls $(29 \mathrm{~cm})$ were made of stainless steel. The front wall had an operant lever and a recessed food cup, neither of which was used. The side walls $(23.5 \mathrm{~cm})$ and ceiling were made of clear acrylic plastic. The test chamber was placed inside a sound-attenuating chest. A $30 \times 30 \mathrm{~cm}$ clear plastic window in the chest allowed for 
observation. A fan attached to the chest provided ventilation and a background noise level of $74 \mathrm{~dB}$ (C scale).

The floor of the chamber was composed of 18 stainless steel rods, $2.5 \mathrm{~mm}$ in diameter and spaced $1.5 \mathrm{~cm}$ center to center. Each rod was wired to a Grason-Stadler shock generator/scrambler, which provided a .75-sec shock. The chamber was illuminated by a 7.5-W white light bulb attached to the ceiling of the sound-attenuating chest. The bulb was $12.5 \mathrm{~cm}$ above the center of the test chamber's ceiling. Between subjects, the chamber was cleaned with a paper towel moistened with a solution of $5 \%$ ammonium hydroxide and tap water.

Procedure. The 1st day of the experiment was the training day. A rat was removed from its home cage and placed in the test chamber. Three minutes later, it received four shocks $(1 \mathrm{~mA})$ at a 20-sec intershock interval (ISI). Thirty seconds after the last shock, the rat was returned to its home cage.

The test day occurred $24 \mathrm{~h}$ later. The rat was returned to the test chamber and $3 \mathrm{~min}$ later was given a single shock. The rat was removed from the chamber $8 \mathrm{~min}$ after that shock. For one third of the rats, this shock was .4 mA; for another third, it was $1.0 \mathrm{~mA}$; and for the remaining third, the shock was $1.6 \mathrm{~mA}$.

Data were collected throughout the 11-min test session by an observer using a time sampling procedure similar to those described elsewhere (Bouton \& Bolles, 1980; Fanselow \& Bolles, 1979b; Sigmundi, Bouton, \& Bolles, 1980). Every $1.25 \mathrm{sec}$, the rat's behavior was judged as being either freezing or activity. Freezing was defined as the absence of all visible movement of the body and vibrissae, except for movement necessitated by respiration. All other behaviors were scored as activity. Note that if the rat was immobile except for even the slightest sniffing or head movements, it was classified as active.

\section{Results and Discussion}

The data are presented in Figure 1. When placed in the chamber on the test day, all groups showed a moderate and comparable base rate of freezing. The animals froze for $58 \%$ of the samples during the 3-min preshock period, and there were no differences among groups $[\mathrm{F}(2,21)<1]$.

Shock onset immediately disrupted freezing, and freezing did not resume for a period of time following shock offset. The latency to freeze following shock was determined by counting the number of samples between shock offset and the first two consecutive samples judged to be freezing. The two criterion samples were not counted in the latency score. The animals in the 1.6-, 1.0-, and .4-mA groups had mean latency scores of $22.5,12$, and 4.25 samples, respectively. These differences were reliable $[\mathbf{F}(2,21)$ $=18.38, p<.0001]$; all groups differed from one another $[\mathrm{Fs}(1,21)>6.76$, ps $<.02]$. The stronger the shock, the longer it disrupted freezing.

The percentage of samples in which the animals froze during the $8 \mathrm{~min}$ following shock offset was also determined. The animals in the 1.6-, 1.0-, and $.4-\mathrm{mA}$ groups froze for $74.4 \%, 78.6 \%$, and $49.1 \%$ of the samples, respectively. An analysis of variance showed these differences to be reliable $[F(2,21)=$ $3.68, \mathrm{p}<.05]$. The lowest intensity group froze reliably less during the 8-min test period than did the other two groups $[F(1,21)=10.84, p<.004]$, which did not differ $[F(1,21)<1]$. Despite the fact that the immediate effect of the stronger shocks was a longer lasting disruption of freezing, these shocks also resulted in more freezing over the entire postshock period.

\section{EXPERIMENT 2}

Fanselow (1980) has suggested that the freezing component of the postshock reaction is a CR to cues paired with shock and that the activity component is an unconditioned reaction (UR) elicited by the shock. Since it would be expected that a UR would be less affected by repeated trials than would a CR, this view

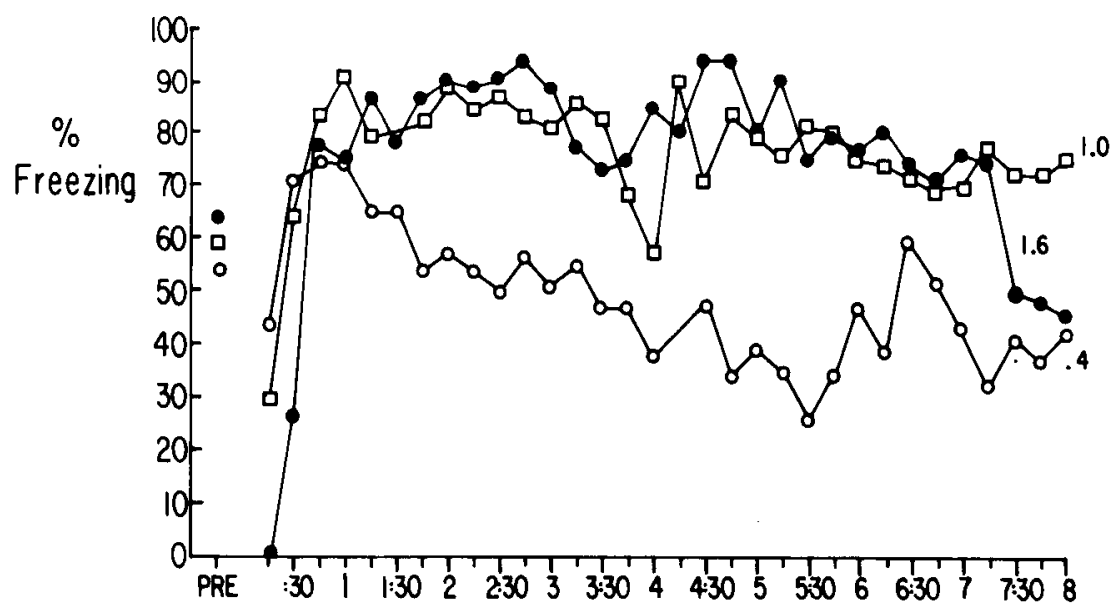

15 Sec Blocks

Fignre 1. The mean percentage of freeding during the test day of Experiment 1. The data for the 8-min postshock period is presented in terms of 15-sec blocks. Pre indicates the 3-min preshock perlod. 
predicts that repeated shock trials will affect freezing more than activity. Consistent with this prediction, Anisman and Waller (1973) found that the activity that occurred $5 \mathrm{sec}$ after shock did not vary as a function of the number of shock trials but that the freezing component that occurred $30 \mathrm{sec}$ after shock did.

Experiment 2 took a different approach to this issue. If shock intensity were varied between the training and testing sessions, it would be expected that a UR would be determined predominantly by the test intensity and that a CR would be determined predominantly by carry-over effects from the training intensity (e.g., Fanselow, 1981, Experiment 2; see Kimble, 1961, p. 118). Therefore, the hypothesis that freezing is a CR and the activity burst a UR predicts that freezing would be affected more by training intensity than by test intensity and that the postshock disruption of freezing would be more affected by test intensity than by training intensity.

\section{Method}

The subjects were 40 rats similar to those of Experiment 1, and the apparatus was the same as that described in Experiment 1.

The procedure was similar to that of Experiment 1, but with the following exception: six shocks $(.75 \mathrm{sec})$, rather than four, were given during training. The animals were randomly assigned, in equal numbers to each cell of a $2 \times 2$ factorial, the factors being training shock intensity (.6 or $1.6 \mathrm{~mA})$ and testing shock intensity (.6 or $1.6 \mathrm{~mA})$.

\section{Results and Discussion}

The data from the test day are presented in Table 1 . A $2 \times 2$ analysis of variance on the percentage of samples judged as freezing for the $3 \mathrm{~min}$ before shock onset indicated a reliable training intensity effect $[F(1,36)=11.22, p<.002]$. Neither the main effect for testing intensity nor the testing $\times$ training intensity interaction was reliable $[F s(1,36)<1]$. The level of preshock freezing was determined by the intensity of shock received on the previous day, with stronger shocks producing more freezing. That freezing occurred prior to shock on the test day is consis-

Table 1

Data of Experiment 2

\begin{tabular}{ccccc}
\hline $\begin{array}{c}\text { Training } \\
\text { Intensity* }\end{array}$ & $\begin{array}{c}\text { Testing } \\
\text { Intensity* }\end{array}$ & $\begin{array}{c}\text { Preshock } \\
\text { Freezing** }\end{array}$ & $\begin{array}{c}\text { Latency to } \\
\text { Resume } \\
\text { Freezing† }\end{array}$ & $\begin{array}{c}\text { Postshock } \\
\text { Freezing** }\end{array}$ \\
\hline .6 & .6 & .44 & 11.1 & .53 \\
.6 & 1.6 & .54 & 17.5 & .65 \\
1.6 & .6 & .73 & 9.8 & .74 \\
1.6 & 1.6 & .78 & 23.8 & .74 \\
\hline
\end{tabular}

Note-The rats received six shocks at the training intensity and one shock at the testing intensity. $\quad$ *Shock intensity in milliamperes. **Proportion of samples scored as freezing. tMean number of samples occurring following shock prior to two consecutive freezes. tent with the view that freezing is a CR to apparatus stimuli associated with shock.

The latency to freeze following shock was determined in the same manner as in Experiment 1. A $2 \times 2$ analysis of variance indicated a reliable effect only for testing intensity $[F(1,36)=4.14, p<.05]$. The training intensity effect and the interaction were not reliable $[F s(1,36)<1]$. Stronger shock resulted in a longer disruption of freezing, but the previous day's shock intensity level was not a significant determinant of this activity burst.

The longest activity burst for any animal was 66 samples (an animal in the 1.6-/1.6-mA group). For each animal, the percentage of samples judged as freezing from the 67th postshock sample to the 384th postshock sample was determined. This metric should provide a measure of posttest-shock freezing that is free from the influence of the activity burst. The training, testing, and interaction effects were not reliable sources of variance. Only the training effect approached significance $[F(1,36)=3.29, p=.078]$. Thus, there was a trend similar to that observed for freezing during the $3 \mathrm{~min}$ prior to shock (see Table 1).

All these data are consistent with the view that the activity following shock and the accompanying disruption of freezing are URs to shock and that freezing is a CR to stimuli present in the testing situation.

\section{EXPERIMENT 3}

Fanselow (1980) has argued that postshock freezing is entirely a CR produced by stimuli paired with shock but is in no part a UR elicited by the shock itself. His finding that freezing was greatly reduced by testing an animal in the absence of stimuli that had been contiguous with shock suggested that this response was a CR (see also Blanchard \& Blanchard, 1969; Bolles \& Collier, 1976; Fanselow, 1981). Evidence that freezing was not a UR came from his finding that freezing was not reduced by imposing a $24-\mathrm{h}$ delay (spent in the animal's home cage) between shock offset and testing. Such a delay should have allowed any UR to shock to dissipate.

Since the animals with the 24-h delay had to be handled when they were removed from the test chamber, Fanselow (1980) handled both the delayed group and the nondelayed control group between shock and testing. It is possible that this handling procedure disrupted any unconditioned component of freezing and thereby eliminated an effect of delay on freezing. Experiment 3 tested this possibility.

The rats received four shocks in the test apparatus and then were observed for freezing. Some animals were handled between shock offset and observation, while others were not. Some of the animals were observed immediately after shock, while others were observed 2 days after shock. 


\section{Method}

Eighteen rats similar to those in Experiment 1 were tested in the same apparatus as in Experiment 1.

The rats were placed in the test chamber, and 2 min later they received four shocks (.75 sec, $.5 \mathrm{~mA})$ at a 20 -sec ISI. One-third of the rats received both handling and a delay between shock and testing. After the last shock they were removed from the test chamber and replaced in their home cages. Forty-eight hours later they were returned to the test chamber for the observation period. One-third of the rats received similar handling but no delay. They were removed from the test chamber and immediately replaced for the observation period. The final one-third received no handling and no delay between shock offset and the observation period. They remained, undisturbed, in the test chamber, and, because handling took about $20 \mathrm{sec}$, observation began $20 \mathrm{sec}$ later.

The observation period was $8 \mathrm{~min}$. Every $4 \mathrm{sec}$ the rat's behavior was judged as either freezing or activity.

\section{Results}

The percentage of samples judged as freezing for each minute of the observation period was determined and is presented in Figure 2. These data were subjected to a 3 (between groups) $\times 8$ (repeated measures) analysis of variance. The overall betweengroups effect was not reliable $[\mathrm{F}(2,15)<1]$.

The within-subjects variable for minutes was reliable $[F(7,105)=16.40, p<.0001]$. There were reliable quadratic $[F(1,105)=29.05, p<.001]$ and linear $[F(1,105)=73.8, p<.0001]$ components to this minute effect. Freezing increased from the 1 st to the 2nd minute but began a linear decrease after the 3rd minute (a similar temporal pattern for freezing has been reported by Fanselow \& Bolles, 1979a). The group $x$ minute interaction was not reliable $[F(14,105)=1.06]$.

\section{Discussion}

Fanselow (1980) found that a 24-h delay between shock offset and testing did not reduce freezing. In

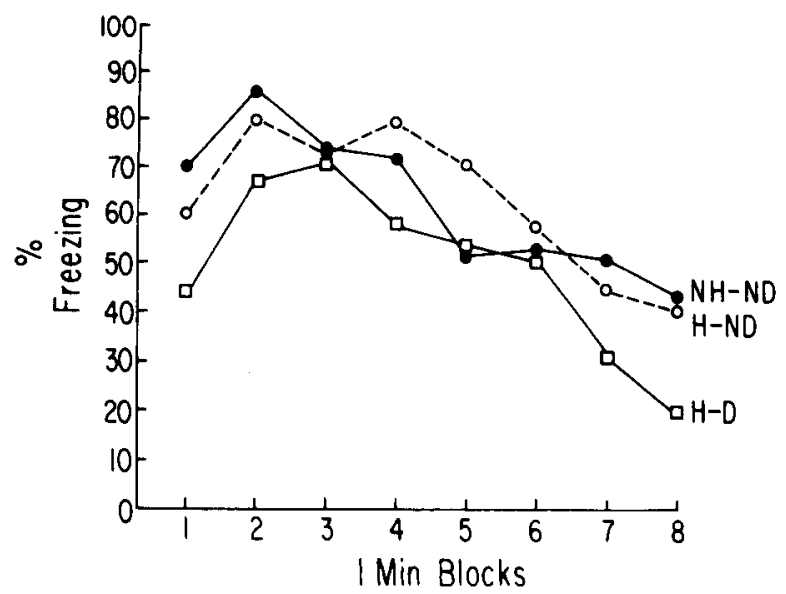

Figure 2. The mean percentage of freexing during each minute of the 8-min observation period of Experiment 3. NH-ND refers to the group that recelved no handling and no delay; $H-N D$ refers to the group that was handled but tested with no delay; and H-D refers to the group that recelved both handling and a delay. fact, it was found that with a 1.0-mA shock the 24-h delay actually increased freezing but with a .5-mA shock the delay had no effect. The present results extend these findings, in that a 48-h delay between a .5-mA shock and testing was found to have no effect on freezing. The present design also ruled out the possibility that handling disrupted the unconditioned component of freezing. The inability of such a delay to reduce freezing argues against the existence of an unconditioned component of the freezing response and is consistent with the hypothesis that freezing is a CR to stimuli paired with shock but not a UR to the shock itself.

In this experiment, there was a 20-sec delay between shock offset and testing, even in the no-delay groups. One could argue that an unconditioned component of freezing exists but lasts less than 20 sec. However, it is during that 20-sec period that shock produces its disruption of freezing (see Experiments 1 and 2). The existence of a brief, unconditioned freezing response to shock is, therefore, unlikely.

\section{EXPERIMENT 4}

In Experiments 1 and 2, the activity that followed shock was described solely in terms of the disruption of freezing. The purpose of Experiment 4 was to describe the behaviors that compose the activity burst. A more detailed observation procedure was used, one comprising several behavioral categories, and both total duration and frequency of all behaviors were determined.

If the activity burst is an unconditioned reaction to grid shock, it should be manifest without training. Therefore, Experiment 4 looked for changes in behavior that occurred immediately following the first shock the animals received. The animals were also tested for shock-elicited changes in behavior following a history of prior shocks in the chamber. This was done to provide a detailed description of the behaviors that constituted the activity burst found in Experiments 1 and 2 .

The animals' behavior for the $20 \mathrm{sec}$ immediately before onset of a shock was compared with their behavior for the $20 \mathrm{sec}$ following shock offset. This brief interval was chosen so that it would reflect predominantly the activity, as opposed to the freezing, component of the postshock reaction.

\section{Method}

Seven rats, like those described earlier, were run in the same apparatus that was used in the previous experiments.

On Day 1, a rat was placed in the chamber and 3 min later was given a single $1.6-\mathrm{mA}, .75-\mathrm{sec}$ shock. It was removed from the apparatus $20 \mathrm{sec}$ later. On Day 2, the rat was returned to the chamber and 3 min later was given six shocks identical to those received on Day 1 , at a $20-\mathrm{sec}$ ISI. Twenty seconds after the last shock, it was removed from the chamber. Day 3 was a replication of Day 1.

The animals were observed on Days 1 and 3; only the data 
for the $20 \mathrm{sec}$ preceding shock onset and the $20 \mathrm{sec}$ following shock offset were analyzed. An exhaustive list of mutually exclusive behavioral categories was constructed. Each time the animals' behavior shifted between categories, the observer said the name of the new behavioral category into a tape recorder. The tape was later analyzed to determine the frequency and duration of all behaviors. The names and definitions of all the behavioral categories that occurred during the two 40 -sec observation periods appear in Table 2.

\section{Results}

The mean percentage of time the animals spent in each behavioral category is presented in Table 2 . The duration and frequency data of each category were subjected to one-factor, repeated-measures analyses of variance with four levels, the levels being the $20 \mathrm{sec}$ prior to the first shock on Day 1 (Pre 1), the $20 \mathrm{sec}$ following shock on Day 1 (Post 1), the $20 \mathrm{sec}$ prior to shock on Day 3 (Pre 2), and the $20 \mathrm{sec}$ following shock on Day 3 (Post 2). If the overall $F$ was reliable, the data were subjected to a set of orthogonal comparisons. Only behavioral categories for which the overall $F$ was reliable will be discussed further. The results for those behavioral categories are presented in Table 3.

The set of orthogonal comparisons contained the following tests: (1) Pre 1 was compared with Pre 2. Since the Pre periods followed shock by at least $24 \mathrm{~h}$, they should not reflect a UR to shock. Since Pre 1 was before any shock experience, whereas Pre 2 fol-

\section{Table 2}

\section{Behavlors Observed in Experiment 4}

\section{FREEZE (32.5\%)}

2. $\operatorname{HEAD}(17.9 \%)$

3. $\operatorname{REAR}(17.7 \%)$

4. TURN $(11.4 \%)$

5. SNIFF $(10 \%)$

\section{WALK $(7 \%)$}

7. DOWN $(2.8 \%)$

8. STRETCH $(.6 \%)$

9. GROOM $(.09 \%)$
The immobility posture described earlier. Movement, usually from side to side, of the head while the rest of the body is immobile.

Standing on hind paws with front paws lifted off the floor.

\section{Turning about a vertical axis.}

Active sniffing of walls, corners, etc. This behavior was characterized by forward and back and/or side-to-side movements of the head. This behavior was often accompanied by front paw movement.

Forward ambulatory movement involving hind legs. This category consists of both running and walking.

A brief transition state that occurs when front paws are returned to the floor after rearing but before the next behavior (often another rear) occurs.

With the hind legs stationary, the animal stretches its body, head, and forepaws out horizontally.

Any scratching, licking, or washing of the body. Only one rat scratched itself (once before the first shock). No other instances of grooming were observed. lowed considerable shock experience, a reliable difference for this comparison should reflect a CR. (2) Pre 1 and Pre 2 combined were contrasted with Post 1 and Post 2 combined. A reliable difference on this comparison should reflect a behavioral change elicited by shock (i.e., a UR). (3) Post 1 was compared with Post 2 . This would reflect a change in the UR to shock as a result of repeated shock presentations. This could be due to habituation to shock or an interaction between the UR and the developing CR.

Freeze. More time was spent freezing during Pre 2 than during Pre $1[\mathrm{~F}(1,18)=63.45, \mathrm{p}<.001]$, indicating again that freezing is a CR. The total duration of freezing was greater in the Pre periods than in the Post periods $[\mathrm{F}(1,18)=12.44, \mathrm{p}<.002]$, indicating that part of the UR to grid shock is a disruption of freezing. The duration of freezing did not differ between Post 1 and Post $2[\mathrm{~F}(1,18)=1.09]$. The frequency of freezing (i.e., the number of individual bouts of freezing) was greater in Pre 2 than in Pre 1 $[F(1,18)=10.71, p<.004]$. The number of bouts of freezing did not differ for Pre $1+$ Pre 2 vs. Post 1 + Post $2[F(1,18)=1.65]$. This was due to the occurrence of some freezing toward the end of the 20 -sec postshock periods and probably marks the transition between the activity and inactivity components of the reaction. The number of freezing bouts did not differ between Post 1 and Post $2[\mathrm{~F}(1,18)<1]$.

Head. The Pre 1 vs. Pre 2 comparison was not reliable for either duration $[\mathrm{F}(1,18)<1]$ or frequency $[\mathrm{F}(1,18)<1]$ of head movement. However, the Pre 1 + Pre 2 vs. Post $1+$ Post 2 comparison was reliable for both duration $[F(1,18)=20.08, p<.0003]$ and frequency $[F(1,18)=35.43, p<.0001]$. This suggests that an increase in the head-movement category is a component of the UR to shock. The duration of head movement was greater during Post 1 than during Post $2[F(1,18)=4.64, p<.05]$, but there was no reliable difference in frequency.

Rear. That both the duration $[F(1,18)=6.42$, $\mathrm{p}<.025]$ and frequency $[\mathrm{F}(1,18)=15.09, \mathrm{p}<.001]$ of rearing were greater in Pre 1 than in Pre 2 indicates that a reduction in rearing characterized the CR. The Pre 1 + Pre 2 vs. Post $1+$ Post 2 comparison was not reliable for either duration $[F(1,18)$ $<1]$ or frequency $[F(1,18)=1.61]$. Although the duration of rearing was reliably greater in Post 2 than in Post $1[F(1,18)=9.42, p<.007]$, the difference in frequency was not $[F(1,18)=2.23]$. Shock on Day 1 seemed to suppress the duration of rearing, whereas shock on Day 3 seemed to increase the duration of rearing.

Turn. Turning behavior was totally absent during Pre 2, suggesting that one component of the conditioned fear response is a suppression of turning. This Pre 1 vs. Pre 2 difference was reliable for frequency 
Table 3

Data of Experiment 4

\begin{tabular}{|c|c|c|c|c|c|c|c|c|}
\hline \multirow[b]{2}{*}{ Behavior } & \multicolumn{4}{|c|}{ Duration } & \multicolumn{4}{|c|}{ Frequency } \\
\hline & Pre 1 & Post 1 & Pre 2 & Post 2 & Pre 1 & Post 1 & Pre 2 & Post 2 \\
\hline Freeze & .0 & 2.2 & 18.3 & 4.6 & .0 & .9 & 1.3 & 1.1 \\
\hline Head & .0 & 8.8 & 1.0 & 4.2 & .0 & 2.3 & .3 & 1.6 \\
\hline Rear & 5.7 & .6 & .5 & 6.9 & 2.1 & .4 & .3 & 1.1 \\
\hline Turn & 1.8 & 6.0 & .0 & 1.1 & 1.6 & 2.3 & .0 & .7 \\
\hline Sniff & 7.4 & .4 & .0 & .0 & 2.4 & .1 & .0 & .0 \\
\hline Walk & 1.8 & 1.4 & .2 & 2.1 & 1.6 & 1.3 & .1 & 1.4 \\
\hline Total Changes & & & & & 9.0 & 7.7 & 2.0 & 6.6 \\
\hline
\end{tabular}

Note-The mean total number of seconds engaged in a behavior (duration) and the mean number of instances of that behavior (frequency) for the behavioral categories for which reliable differences were found. Total changes are the mean numbers of times the animals switched from one category to another. Pre 1, Post 1, Pre 2, and Post 2 refer to the 20 sec before shock on Day 1, the $20 \mathrm{sec}$ following shock offset on Day 1, the $20 \mathrm{sec}$ before shock on Day 3, and the 20 sec following shock offset on Day 3, respectively.

$[F(1,18)=7.03, p<.017]$ but not for duration $[F(1,18)=1.37]$.

Significantly more time was spent turning during the postshock periods than during the preshock periods $[F(1,18)=6.27, p<.023]$, but the frequency of this behavior did not change reliably $[F(1,18)=$ $2.9, p>.10]$. Both the frequency $[F(1,18)=7.03$, $\mathrm{p}<.02]$ and total duration $[\mathrm{F}(1,18)=6.27, \mathrm{p}<.023]$ of this behavior were greater during Post 1 than during Post 2. Shock appears to elicit an increase in turning, and this effect is more apparent after one shock than after eight shocks.

Sniff. The duration $[\mathrm{Fs}(1,18)>22.93$, ps $<.002]$ and frequency $[F s(1,18)>28.4$, ps $<.0001]$ of sniffing were greater during Pre 1 than during any of the other periods, which did not differ among each other. Apparently, the first shock conditioned enough fear to eliminate sniffing in the test apparatus.

Walk. The only result for the frequency of walking was that it was less in Pre 2 than in any other period $[\mathrm{Fs}(1,18)>6.71$, ps $<.019]$. The duration of walking was less in Pre 2 than in Pre $1[\mathrm{~F}(1,18)=$ $10.02, \mathrm{p}<.006$ ]. Part of the CR to cues paired with shock is a suppression of walking. There was more walking in the postshock periods than in the preshock periods $[F(1,18)=7.43, p<.014]$, while the two postshock periods did not differ $[F(1,18)=1.93]$. Walking or running may be a component of the response elicited by shock.

The total number of behavior changes was also determined and is presented as the last row in the frequency section of Table 3 . The rats changed their behavior fewer times during Pre 2 than during any other period $[F s(1,18)>9.8$, ps $<.006]$. Part of the conditioned reaction to shock appears to be a hesitancy to change behavior.

The down, stretch, and groom categories showed no reliable differences between periods. This lack of statistical significance may reflect a floor effect for these behaviors; combined, they occupied only $3.49 \%$ of the animals' behavior.

\section{Discussion}

In summary, the $C R$ to shock seems to be that freezing behavior replaces rearing, turning, sniffing, and walking. Head movement and turning appear to be the predominant unconditioned reactions following the first shock. With further shock experience, the US appears to elicit head movement and rearing. Shock reduced the duration of freezing in Post 2 to $25 \%$ of that in Pre 2 . Of that $75 \%$ disruption of freezing, $81 \%$ of it was due to head movement and rearing activity.

Because of the very brief shocks used, I did not attempt to quantify behavior during the shock itself. Qualitatively, the behavior during shock, in all four experiments, was characterized by reflexive paw withdrawal, jumping, and squealing. Throughout shock, the animal moved rapidly, although in an uncoordinated manner, about the chamber. This movement persisted for a fraction of a second beyond shock termination and then gave way to the behaviors described above. Using a photocell arrangement and prolonged (6-sec) grid shock, Anisman, deCatanzaro, and Remington (1978) found that shock caused an immediate increase in activity that declined over the course of the shock. A similar pattern of increased activity followed by inactivity was noted by Glazer and Weiss (1976) over the course of a 6-sec tailshock. However, in a thorough observational analysis of behavior during prolonged grid shock, Blanchard and Blanchard (1969) found that this "inactivity" during shock does not consist of crouching or freezing. Rather, the Blanchards reported an increase in "standing" over the course of a long shock. In my own unpublished observations of animals receiving prolonged shocks, I have confirmed the Blanchards' findings. Freezing is never seen during shock; rather, the reflexive activity is increasingly, as shock continues, interrupted by the animals' holding in "cold" spots, such as rearing with its front paws on an unelectrified wall. Thus, the immediate activity and consequent inactivity that 
occurs during a prolonged shock appears to be topographically distinct from the immediate activity and subsequent freezing that follows shock offset.

\section{GENERAL DISCUSSION}

Taken as a whole, these data provide a description of the activities of a rat receiving grid shock. The initial shock suppresses the rat's ongoing activity; the rat becomes immobile except for side-to-side head movements (head) and rotating about in one spot (turning). Eventually, the animal's behavioral repertoire is dominated by freezing, but subsequent shocks temporarily disrupt freezing. The length of this disruption depends on the intensity of the test shock and is characterized by head movement and rearing. It is interesting to note that, on a leverpress escape task, the force the rat places on the bar follows a pattern that resembles the overt behavior reported here. Shock elicits an immediate reflexive lurch (Bolles \& McGillis, 1968; Davis, 1979; Davis \& Burton, 1974). For a brief period following shock offset, the force placed on the bar fluctuates (the postshock activity burst) but eventually steadies as the rat freezes on the bar (Davis \& Burton, 1974).

Several features of the postshock activity burst suggest that it is an unconditioned reaction to grid shock. The first grid shock elicits behaviors that are components of the activity burst in response to later shocks (Experiment 4). The duration of the activity burst is determined by the testing, but not training, intensity of shock (Experiment 2). Finally, Anisman and Waller (1973) found that the level of activity during this burst does not vary with repeated shock trials.

Three findings in this series of experiments indicate that freezing is a conditioned reaction to shockassociated stimuli: (1) The freezing response is predominantly determined by the intensity of the training shock (Experiment 2). (2) This behavior is not reduced by a delay between testing and training (Experiment 3). (3) Freezing occurs in response to cues paired with shock (i.e., it occurred on the test day, prior to the shock in Experiments 1 and 2). The suggestion that freezing is a CR is also consistent with earlier reports that postshock freezing increases as a function of the number of training trials (Anisman \& Waller, 1973; Fanselow \& Bolles, 1979a) and that it is dependent upon the presence of shockpaired stimuli (Fanselow, 1980, 1981). Although in the present situation shock-associated stimuli produced freezing, it would be an oversimplification to view the response to conditioned fear as a mere inhibition of activity. With appropriate modifications in behavioral support stimuli (Tolman, 1932), fear may manifest itself in very active defensive behaviors such as locomotion (Bolles \& Collier, 1976) or burying (Pinel \& Treit, 1978).

\section{REFERENCES}

Anisman, H., deCatanzano, D., \& Remington, G. Escape performance following exposure to inescapable shock: Deficits in motor response maintenance. Journal of Experimental Psychology: Animal Behavior Processes, 1978, 4, 197-218.

Anisman, H., \& Waller, J. G. Footshock-produced excitation and inhibition of activity in rats. Animal Learning Behavior, $1973,1,93-95$.

Blanchard, R. J., \& Blanchakd, D. C. Crouching as an index of fear. Journal of Comparative and Physiological Psychology, $1969,67,370-375$.

Blanchard, R. J., Dielman, T. E., \& Blanchand, D, C Postshock crouching: Familiarity with the shock situation. Psychonomic Science, 1968, 10, 371-372.

Bolles, R. C. Theory of motivation (2nd ed.). New York: Harper \& Row, 1975.

Bolles, R. C., \& Collier, A. C. Effect of predictive cues on freezing in rats. Animal Learning \& Behavior, 1976, 4, 6-8.

Bolles, R. C., \& McGILL13, D. B. The non-operant nature of the barpress escape response. Psychonomic Science, 1968, 11, 261-262.

Boltes, R. C., \& RiLeY, A. L. Freezing as an avoidance response: Another look at the operant-respondent distinction. Learning and Motivation, 1973, 4, 268-275.

Bouton, M. E., \& Bolles, R. C. Conditioned fear assessed by freezing and by the suppression of three different baselines. Animal Learning \& Behavior, 1980, 8, 429-434.

DAvis, H. Leverpress escape behavior in a clinically unconscious rat. Physiology \& Behovior, 1979, 22, 599-600.

Davis, H., \& Burton, J. The measurement of response force during a lever-press shock-escape procedure in rats. Journal of the Experimental Analysis of Behavior, 1974, 22, 433-440.

Fanselow, M. S. Conditional and unconditional components of post-shock freezing. Pavlovian Journal of Biological Science, $1980,15,177-182$.

Fanselow, M. S. Naloxone and Pavlovian fear conditioning. Learning and Motivation, 1981, 12, 398-419.

Fanselow, M, S., \& Bolles, R. C. Naloxone and shock-elicited freezing in the rat. Journal of Comparative and Physiological Psychology, 1979, 93, 736-744. (a)

Fanselow, M. S., \& Bolles, R. C. Triggering of the endorphin analgesic reaction by a cue previously associated with shock: Reversal by naloxone. Bulletin of the Psychonomic Society, 1979, 14, 88-89. (b)

Glazen, H. I., \& WEIss, J. M. Long-term and transitory interference effects. Journal of Experimental Psychology: Animal Behavior Processes, 1976, 2, 191-201.

Kimale, F. A. Hilgard and Marquis' conditioning and learning (2nd ed.). New York: Appleton-Century-Crofts, 1961.

MYER, J. S. Some effects of noncontingent aversive stimulation. In F. R. Brush (Ed.), A versive conditioning and learning. New York: Academic Press, 1971.

Pinel, J. P., \& Treit, D. Burying as a defensive response in rats. Journal of Comparative and Physiological Psychology, $1978,92,708-712$.

Siomundi, R. A., Bouton, M. E., \& Bolles, R. C. Conditioned freezing in the rat as a function of shock intensity and CS modality. Bulletin of the Psychonomic Society, 1980, 15, 254-256.

Tolman, E. C. Purposive behavior in animals and men. New York: Century, 1932.

(Manuscript received May 18, 1982;

revision accepted for publication July 29, 1982.) 